\title{
Nonlinear Optimal Control of Continuously Variable Transmission Powertrain
}

\author{
Reza Kazemi, Mohsen Raf'at, and Amir Reza noruzi \\ Deptartement of Mechanical Engineering, K. N. Toosi University of Technology, Tehran P.O. Box 19395-1999, Iran \\ Correspondence should be addressed to Reza Kazemi; kazemi@kntu.ac.ir
}

Received 31 May 2013; Accepted 14 July 2013; Published 1 January 2014

Academic Editors: A. Lidozzi and D. Sanders

Copyright (C) 2014 Reza Kazemi et al. This is an open access article distributed under the Creative Commons Attribution License, which permits unrestricted use, distribution, and reproduction in any medium, provided the original work is properly cited.

Optimization of gear ratio with the objectives of fuel consumption reduction and vehicle longitudinal performance improvement has been the subject of many studies for years. Finding a strategy for changing gears with specific control objectives, especially in the design of vehicles equipped with Continuously Variable Transition system (CVT), which has advantage of arbitrary selection of gear ratio, has been the aim of some recent researches. Optimal control theory has rarely been used in the previous control approaches applied to such systems due to the limitations in the use of fast computational systems. The aim of this study is to design the aforementioned gear ratio change strategy and related control rules on the basis of optimal control. A driver model is also designed for the simulation of driving cycle using MATLAB Simulink Toolbar. Results of implementing optimal control rules in vehicle longitudinal movement simulation with the aim of fuel consumption reduction are finally represented. The presented method has the remarkable advantage of considerable fuel consumption reduction in comparison to other proposed approaches for gear ratio change strategies.

\section{Introduction}

Continuously variable transmission (CVT) is an attractive technology and has become more practical with recent improvements in the technology. CVT is effective in achieving continuously smooth shifting and enables the engine to operate in its most efficient state. CVT has now reached a level that permits a large-scale usage of these devices even in a fullsize passenger car class. Maximum torques of approximately $300 \mathrm{Nm}$ can be handled with push belts (cf. Gesenhaus, 2000, or Goppelt, 2000). Other systems (e.g., toroidal drives), which cover even larger torque ranges, have been proposed as well.

Although the efficiencies of CVT are inherently lower than those of $\operatorname{cog}$ wheel gear boxes, a more efficient totalsystem behavior can be obtained by shifting the engine operating points for a certain demanded power towards higher loads and lower speeds.

A reliable method of control system design is usually trial and error in which different iterative methods are used for determining design parameters of an acceptable system.
Appropriate performance of the system is usually introduced by some characteristics such as rising time, settling time, and overshoot or with some frequency characteristics such as phase margin, gain margin, and band width. With this method for multi-input multioutput systems, different criteria or performance characteristics for achieving the technological requirements are needed. For example, plane position plan control which minimizes fuel consumption is not possible with usual techniques. A direct method for introducing these complex systems is called optimal control and it has been a practical solution using digital computers. The objective of optimal control is to determine the control signals which satisfy mechanical constrains and maximize or minimize performance or special criteria.

\section{Complete Detailed CVT Powertrain Modeling}

The powertrain is modeled in its longitudinal behavior with minimum simplification being taken into account.

This model is appropriate to test control unit operation after applying on vehicle longitudinal dynamic. 


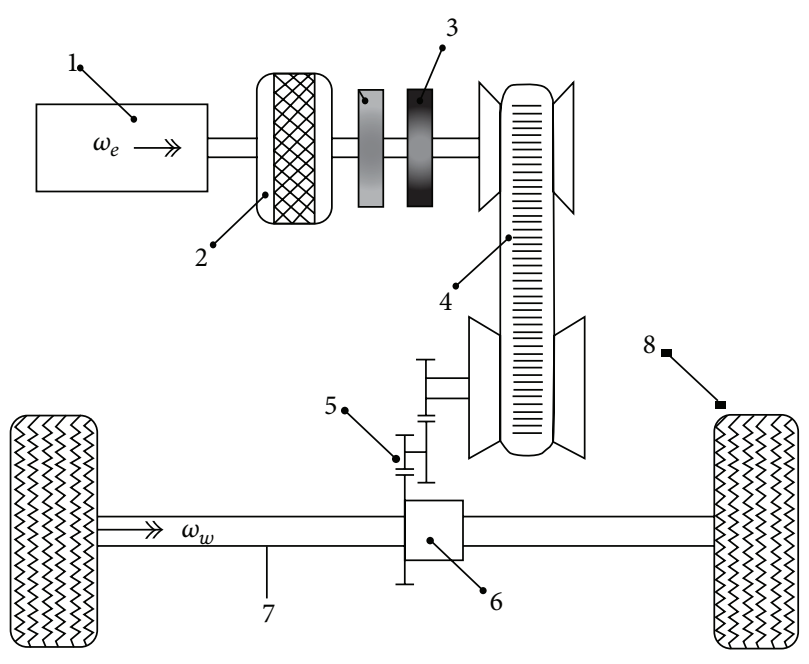

FIGURE 1: Schematic of CVT powertrain subsystems.

Powertrain subsystems are the following as shown in Figure 1:

(1) internal combustion engine,

(2) torque converter,

(3) DNR,

(4) CVT,

(5) final reduction,

(6) differential,

(7) drive shaft,

(8) tires.

2.1. Internal Combustion Engine. The mean-value model of an engine describes the engine behavior in a cycle averaged sense. Though it does not contain individual cylinder transient dynamics, the average of engine dynamics over several cycles provides adequate low-frequency dynamic information and it is suitable for many control problems. Figure 2 depicts a schematic of the mean-value engine model including throttle airflow dynamics, intake manifold dynamics, fuel film dynamics, engine torque production, and crankshaft dynamics.

The time domain mean-value engine model, introduced in the next section, assumes that exhaust gas recirculation (EGR) depends internally on variable valve timing (VVT) and spark advance (SA) remains constant in certain operating conditions. Air fuel ratio (AFR) is also well maintained at stoichiometric. Therefore, this engine model is broken down into four subsystems: electronically controlled throttle body, intake manifold, combustion, and crank shaft Dynamics neglecting fuel dynamics [1].

Intake Manifold. The intake manifold is the plenum between the ETB and the engine cylinders. Equation describes a mean-value filling and emptying intake model based on the continuity principle and the ideal gas law [2]. The total air that goes into the cylinders is expressed in an empirical equation.
Fuel dynamics are not modeled here since engine air fuel ratio (AFR) is always well maintained at stoichiometric operating conditions [3].

Fuel consumption is thus calculated as the total air mass flow rate entering the cylinders divided by

$$
\begin{gathered}
\dot{m}_{a}=\dot{m}_{a i}-\dot{m}_{a o}, \\
\dot{m}_{a i}=\mathrm{MAX} \cdot \mathrm{TC} \cdot \mathrm{PRI}, \\
\mathrm{TC}= \begin{cases}1-\cos (1.14459 \alpha-1.06) & \alpha \leq 79^{\circ}, \\
1 & \alpha \geq 79^{\circ},\end{cases} \\
\mathrm{PRI}=1-\left(\exp \left(9 \frac{P_{m}}{P_{\mathrm{atm}}}\right)-1\right), \\
V_{m} \frac{d P_{m}}{d t}=\dot{m}_{a} R T_{m}, \\
\dot{m}_{\infty}=C_{1} \cdot \eta_{\mathrm{VOl}} \cdot m_{a} \cdot \omega_{e}, \\
C_{1}=\frac{V_{e}}{4 \pi V_{m}} .
\end{gathered}
$$

Combustion. Engine combustion takes air and fuel as inputs and produces torque and exhausts with losses. Torque production from combustion is usually estimated by a regression model that takes air flow, SA, AFR, and engine speed into account. Since AFR is assumed to be constant in this model, its effect on produced torque is combined into $T_{0}$ term. The engine torque therefore becomes $T_{e} . T_{e}$ in equation is the engine brake torque which considers both engine production and friction torques. Air in this equation is delayed by $\mathrm{td}$ which varies in the time domain due to varying.

Engine speed. The engine torque is bounded by wide open throttle and minimum throttle torques according to:

$$
\begin{aligned}
\eta_{\mathrm{VOI}}=( & \left.24.5 \omega_{e}-3.10 \times 10^{4}\right) m_{a}^{2} \\
& +\left(-0.167 \omega_{e}+222\right) m_{a} \\
& +\left(8.1 \times 10^{-4} \omega_{e}+0.352\right), T_{i} \\
= & C_{T} \times \frac{\dot{m}_{\infty}\left(t-\Delta t_{i t}\right)}{\omega_{e}\left(t-\Delta t_{i t}\right)} \times \mathrm{AFI}\left(t-\Delta t_{i t}\right) \\
& \times \mathrm{SI}\left(t-\Delta t_{s t}\right), \mathrm{AFI} \\
= & \cos \left(7.3834\left(\frac{A}{F}-13.5\right)\right), \mathrm{SI} \\
= & (\cos (\mathrm{SA}-\mathrm{MBT}))^{2.875} .
\end{aligned}
$$

Crank Shaft. Crank shaft speed dynamics are intrinsically based on Newton's second law for a rotational object; $T_{p}$ in (2) represents the load torque from the torque converter pump. Idle and redline are the physical speed constraints for the engine. These relationships are represented as [1]

$$
I_{e} \dot{\omega}_{e}=T_{i}-T_{p}
$$

2.2. Torque Converter (TC). The primary functions of the torque converter (TC) include torque multiplication to 


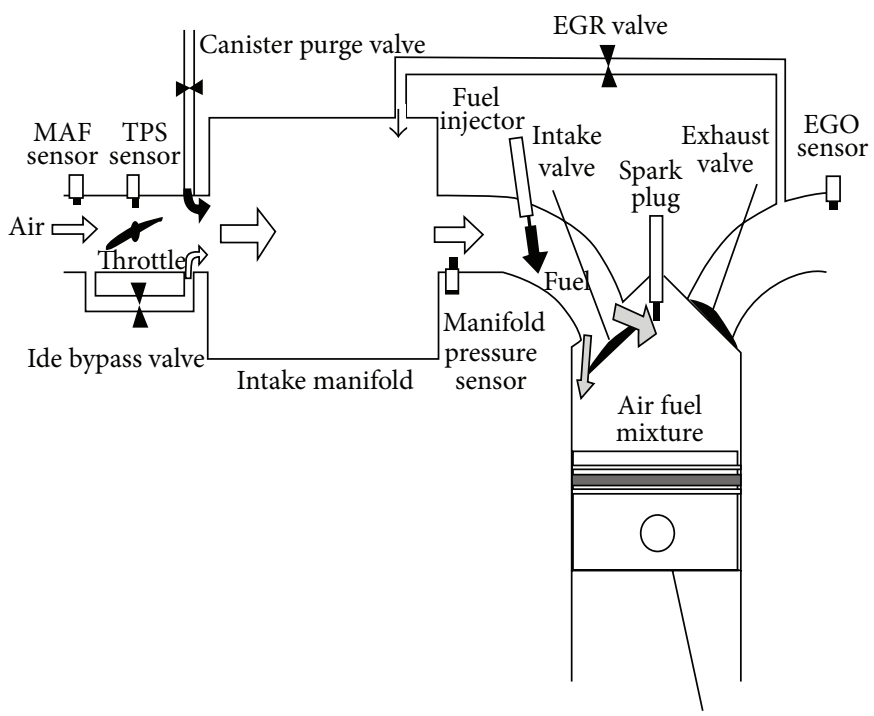

FIGURE 2: Internal combustion engine subsystems [4].

provide sufficient torque during vehicle launch and fluid damping to smooth torque fluctuations in the powertrain. A fluid-filled three-element TC has two phases: torque multiplication phase and fluid coupling phase. The TC impeller (also referred to as the TC pump) is driven by the engine and the turbine is attached to the transmission input shaft. The turbine and the stator that are connected to the TC housing via a one-way clutch are initially at rest during vehicle launch. The turbine speed begins to increase under the angular momentum of the impeller that is transmitted through circulating fluid inside the TC. When the ratio of the turbine speed to the pump speed is low, the stator remains at rest and it redirects the fluid flow in the same direction as the pump torque such that the resulting output torque of the TC is amplified. This is called the torque multiplication or torque amplification phase. At higher turbine speed, the stator rotates freely in the same direction of the pump and it is considered to consume no torque. Therefore, the turbine torque in this torque coupling phase is the same as the pump torque [4].

TC act as hydraulic dampers to interrupt vibration propagation originated from either engines or road bumps and to provide torque multiplication during vehicle launch [5]. Since TC is essentially a damper, losses are not negligible. However, these losses can be reduced by employing a TC bypass clutch, which mechanically connects the TC pump and the turbine when the clutch is engaged. This connection improves TC efficiency at the price of losing the capability to absorb oscillations in the powertrain. A compromising solution is proposed by Kazemi et al., allowing 1 to $2 \%$ of clutch slip to achieve similar results as the TC is working as a damper [4]. Obviously, people desire to minimize this slip for efficiency consideration. This type of bypass clutch is a socalled minimal slip-type TC clutch.

The torque converter is expressed with a regression model based on Kotwicki's research [5]. In this model, there are three modes in the forward drive case (power is flowing from the engine to the wheels) and two modes in the backward drive case (overrun case), and they are shown in (4) to (7).

Forward $\left(\omega_{p}>\omega_{t}\right)$.

(1) Torque multiplication mode $\left(T_{t}>T_{p}\right)$ :

$$
\begin{aligned}
& T_{p}=b_{1} \omega_{p}^{2}+b_{2} \omega_{p} \omega_{t}+b_{3} \omega_{t}^{2}, \\
& T_{t}=c_{1} \omega_{p}^{2}+c_{2} \omega_{p} \omega_{t}+c_{3} \omega_{t}^{2} .
\end{aligned}
$$

(2) Torque coupling mode $\left(T_{t}=T_{p}\right)$ :

$$
T_{p}=T_{t}=a_{1} \omega_{p}^{2}+a_{2} \omega_{p} \omega_{t}+a_{3} \omega_{t}^{2} .
$$

(3) Lockup mode $\left(\omega_{p}=\omega_{t}\right)$ :

$$
T_{t} \leq T_{\text {clutch_max }} .
$$

Backward (overrun) $\left(\omega_{t}>\omega_{p}\right)$.

(1) Torque coupling mode: $\left(T_{t}=T_{p}\right)$

$$
T_{P}=T_{t}=d_{1} \omega_{P}^{2}+d_{2} \omega_{P} \omega_{t}+d_{3} \omega_{t}^{2}
$$

(2) Lockup mode: the same as in the forward drive case.

As shown in Figure 3, this TC has the maximum torque ratio (turbine torque over pump torque) of about 1.65 and the coupling point at the speed ratio (turbine speed over pump speed) of 0.88 . Its efficiency before the coupling point is lower than $90 \%$ and that in the lockup mode is around $99 \%$.

2.3. Continuously Variable Transmission (CVT). A CVT is a continuous speed reduction device with infinite number of transmission ratios between two limits. Comparing the three 


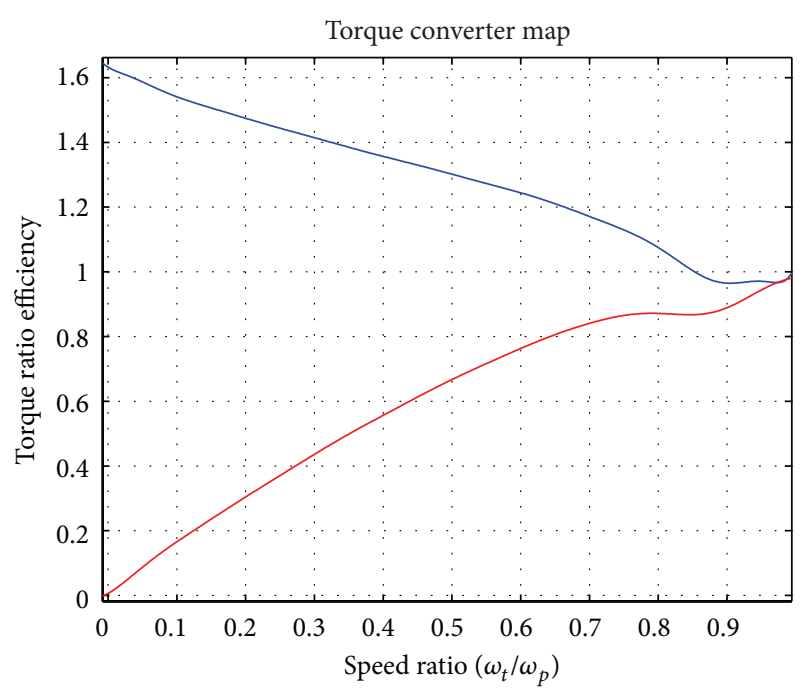

FIGURE 3: Torque converter operating diagram.

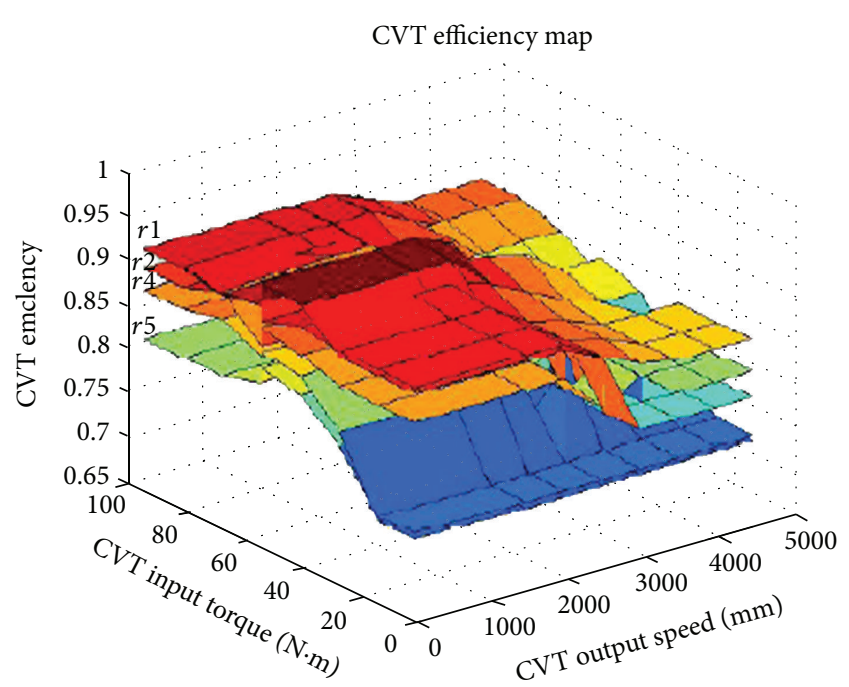

Figure 4: CVT efficiency map [4].

types of the CVTs used in automobiles, that is, mechanical, hydraulic, and electrical, the mechanical CVT is more attractive due to its better performance on efficiency, noise level, size, weight, and cost [6]. Among the mechanical CVTs, the variable pulley CVT is more commercialized than the variable stroke CVT and the traction drive CVT. The variable pulley could be rubber belt, chain, or push-belt and the latter accounts for the largest share of the market.

The CVT ratio can be varied by changing the radii of these two pulleys with a hydraulic control system. Shifting of a push-belt CVT neglecting the dynamics, the CVT is modeled with an efficiency map with speed, torque, and transmission ratio as the arguments [7].

In Figure 4, the CVT has higher efficiency at lower speed, lower CVT ratio, and medium torque. $r 1$ to $r 5$ represent distributed CVT ratios 0.5 to 2.5 . The efficiency at any ratio in between is obtained by using linear interpolation. The efficiency of a steel-belt CVT with special oil containing rubber molecules to lock the belt with the pulley can reach up to $97 \%$, similar to that of a manual transmission [4].

Compared to a powertrain equipped with a stepped-gear transmission, the one with a CVT has better overall efficiency and drivability. A variable pulley type CVT with a metal $V$ belt is introduced here [8]. The input-output speed and torque are expressed as functions of the efficiency and the CVT ratio:

$$
\begin{gathered}
\tau_{\mathrm{CVT}} \frac{d r_{\mathrm{CVT}}}{d t}+r_{\mathrm{CVT}}=r_{\mathrm{CVT} \_ \text {req }}, \\
J_{2} \frac{d \omega_{t}}{d t}=T_{t}-T_{\mathrm{CVT} \_p}, \\
J_{3} \frac{d \omega_{\mathrm{CVT} \_s}}{d t}=T_{\mathrm{CVT} \_p}-T_{f d}, \\
r_{\mathrm{CVT}}=\frac{\omega_{\mathrm{CVT} \_p}}{\omega_{\mathrm{CVT} \_s}}, \\
T_{\mathrm{CVT} \_s}=\eta_{\mathrm{CVT}} \cdot r_{\mathrm{CVT}} \cdot T_{\mathrm{CVT} \_p} .
\end{gathered}
$$

2.4. Final Drive (differential). A final drive is represented as a gear set. The ratio is defined as the final drive speed over the driveshaft speed. Efficiency of the final drive is simplified by taking a constant value:

$$
\begin{gathered}
r_{f d}=\frac{\omega_{\mathrm{CVT} \_s}}{\omega_{d s}}, \\
T_{f d}=\eta_{f d} \cdot r_{f d} \cdot T_{\mathrm{CVT} \_s} .
\end{gathered}
$$

2.5. Driveshaft. Shaft flexibility is modeled as lumped compliance, which is helpful in absorbing oscillations in the powertrain. The nonlinear damper is characterized as a function of driveshaft speed:

$$
\begin{gathered}
\frac{d T_{w h}}{d t}=K_{d s}\left(\omega_{d s}-\omega_{w h}\right), \\
T_{f d}=T_{w h}+D_{1} \omega_{d s}+D_{2} \omega_{d s}^{2} .
\end{gathered}
$$

2.6. Vehicle Longitudinal Dynamics. Resistance forces including aerodynamic drag, rolling resistance, and gravity forces are expressed as follows $[9,10]$ :

$$
\begin{gathered}
F_{t f}-F_{t r}-F_{g}-F_{a}=M \dot{V}, \\
F_{a}=\frac{1}{2} \rho_{\text {air }} C_{d} A_{f} V^{2}, \\
F_{t r}=M g C_{d} \cos (\theta), \\
F_{g}=M g \sin (\theta) .
\end{gathered}
$$

\section{Control-Based Modeling of CVT Powertrain}

Some simplifications in model are taken into account for control design purposes. To have feasible nonlinear optimal control design, these simplifications are necessary. Therefore, 
only nonzero vehicle velocities are assumed; that is, the vehicle launch (which needs a clutch or a torque converter) is not analyzed.

First subsystem taken into account is the engine. A static model of engine is derived to have a map of engine operation and its efficient performance in all regions of throttle opening and engine rotational speed [11].

Next supposition is the state of torque converter operation and it is assumed to be in locked state. Driveshaft is supposed to be rigid and input torque is equal to output torque in this part. Other subsystems are similar as mentioned in Section 2 [12].

\section{Optimal Control Theory Overview}

The objective of optimal control is to determine control signals that will cause the system to minimize or maximize some performance criteria while satisfying the physical constraints [13]. Performance criteria, in general, are expressed by the cost function $J=0$ for a system of $x=f(x, u, t)$. The variables $t_{0}$ and $t_{f}$ are the initial and final time, $h$ and $g$ are scalar functions and $t_{f}$ may be fixed or free depending on the problem statement.

Starting from the initial value $x\left(t_{0}\right)=x_{0}$ and applying the optimal control $u^{*}(t)$ for $t \in\left[t_{0}, t_{f}\right]$, the system will follow some state trajectory with minimum cost. (The superscript asterisk on $x, \lambda$ and $u$ represents the optimal trajectories for state, costate, and control variables.) [14].

4.1. Application of the Steeping Descends Method to Optimal Control Problems. Suppose that the nominal control graph $u^{(i)}(t), t \in\left[t_{0}, t_{f}\right]$ was developed for the solution of the flowing differential equations:

$$
\begin{gathered}
\dot{x}^{(i)}(t)=a\left(x^{(i)}(t), u^{(i)}(t), t\right), \\
\dot{p}^{(i)}(t)=-\frac{\partial H}{\partial x}\left(x^{(i)}(t), u^{(i)}(t), p^{(i)}(t), t\right),
\end{gathered}
$$

so that the state-costate equation $x^{(i)}, p^{(i)}$ would meet the following boundary conditions:

$$
\begin{gathered}
x^{(i)}\left(t_{0}\right)=x_{0}, \\
p^{(i)}\left(t_{f}\right)=\frac{\partial h}{\partial x}\left(x^{(i)}\left(t_{f}\right)\right) .
\end{gathered}
$$

It should also be noticed that $x^{(i)}(t), p^{(i)}(t)$, and $u^{(i)}(t)$ will be externals, if the nominal control graph satisfies the following equation:

$$
\frac{\partial H}{\partial u}\left(x^{(i)}, u^{(i)}, p^{(i)}, t\right)=0 \quad t \in\left[t_{0}, t_{f}\right]
$$

If the last equation is not satisfied, the augmented functional change, $J_{a}$, in the state-costate equation will be defined as [15]

$$
\begin{aligned}
& \delta J_{a}=\left[\frac{\partial h}{\partial x}\left(x^{(i)}\left(t_{f}\right)\right)-p^{(i)}\left(t_{f}\right)\right]^{T} \delta x\left(t_{f}\right) \\
&+\int_{t_{0}}^{t_{f}}\left\{\left[\dot{p}^{(i)}(t)+\frac{\partial H}{\partial x}\right.\right. \\
& \\
&\left.\left(x^{(i)}(t), u^{(i)}(t), p^{(i)}(t), t\right)\right]^{T} \delta x(t) \\
&+\left[\frac{\partial H}{\partial u}\left(x^{(i)}(t), u^{(i)}(t), p^{(i)}(t), t\right)\right]^{T} \delta u(t) \\
&\left.+\left[a\left(x^{(i)}(t), u^{(i)}(t), t\right)-\dot{x}^{(i)}(t)\right]^{T} \delta p(t)\right\} d t
\end{aligned}
$$

in which

$$
\begin{aligned}
& x(t) \triangleq x^{(i+1)}(t)-x^{(i)}(t), \\
& \delta u(t) \triangleq u^{(i+1)}(t)-u^{(i)}(t), \\
& \delta p(t) \triangleq p^{(i+1)}(t)-p^{(i)}(t) .
\end{aligned}
$$

If the above equations are met, then

$$
\delta J_{a}=\int_{t_{0}}^{t_{f}}\left[\frac{\partial H}{\partial u}\left(x^{(i)}(t), u^{(i)}(t), p^{(i)}(t), t\right)\right]^{T} \delta u(t) d t
$$

when $J_{a}$ is the linear part of the increment $\Delta J_{a} \triangleq J\left(u^{(i+1)}\right)-$ $J\left(u^{(i)}\right)$, and the norm $\left\|u^{(i+1)}-u^{(i)}\right\|$ is as $\delta J_{a}$. With the objective of $J_{a}$ minimization, the term $\Delta J_{a}$ should be negative.

If the change in variable $u$ is defined as

$$
\begin{array}{r}
u(t)=u^{(i+1)}(t)-u^{(i)}(t)=-\tau \frac{\partial H^{(i)}}{\partial u}(t), \\
t \in\left[t_{0}, t_{f}\right],
\end{array}
$$

for $u>0$, then,

$$
\delta J_{a}=-\int_{t_{0}}^{t_{f}}\left[\frac{\partial H^{(i)}}{\partial u}(t)\right]^{T}\left[\frac{\partial H^{(i)}}{\partial u}(t)\right] d t \leq 0 .
$$

The integrand is nonnegative for all $t \in\left[t_{0}, t_{f}\right]$.

The equation will be met, if and only if the following equation is satisfied:

$$
\frac{\partial H^{(i)}}{\partial u}(t)=0, \quad t \in\left[t_{0}, t_{f}\right] .
$$

Determining $\delta u$ with infinitesimal $\|\delta u\|$ will assure us of the fact that each least value function will be as small as the previous value. Finally, when $J_{a}$ reachs the relative least value, the vector $\partial H / \partial u$ will be equal to zero in the whole time interval of $\left[t_{0}, t_{f}\right]$. 


\subsection{Optimal Control Approach Algorithm}

4.2.1. Solving State Equations. Consider the following:

$$
\begin{gathered}
\dot{x}^{*}(t)=\frac{\partial H}{\partial p}=a\left(x^{*}(t), u^{*}(t), t\right), \\
x^{*}\left(t_{0}\right)=x_{0} .
\end{gathered}
$$

For solving equations represented above, and determining state variables in whole simulation time when vehicle works on all three state of torque convertor performance, we have used simulation model which is the result of software equation simulation in this software.

\subsubsection{Solving Costate Equation. Consider the following:}

$$
\begin{aligned}
\dot{p}(t)= & -\frac{\partial H}{\partial x}=\left[\frac{\partial a\left(x^{*}(t), u^{*}(t), t\right)}{\partial x}\right]^{T} p^{*}(t) \\
& -\frac{\partial g\left(x^{*}(t), u^{*}(t), t\right)}{\partial x} \\
p^{*}\left(t_{f}\right)= & \frac{\partial h}{\partial x}\left(x^{*}\left(t_{f}\right)\right) .
\end{aligned}
$$

4.2.3. Control Input Modification. After determining state and costate variables related to simulation time for

$$
\begin{aligned}
\frac{\partial H^{(i)}}{\partial u}\left(t_{k}\right)= & {\left[\frac{\partial a\left(x^{(i)}\left(t_{k}\right), u^{(i)}\left(t_{k}\right), t_{k}\right)}{\partial u}\right]^{T} p^{(i)}\left(t_{k}\right) } \\
& +\frac{\partial g\left(x^{(i)}\left(t_{k}\right), u^{(i)}\left(t_{k}\right), t_{k}\right)}{\partial u},
\end{aligned}
$$

modification of control input which is gear ratio, according to equation below we must determine the amount of $\left(\partial H^{(i)} / \partial u\right)\left(t_{k}\right)$ function in all time of simulation, and then we will have

$$
\begin{aligned}
& u^{(i+1)}\left(t_{k}\right)=u^{(i)}\left(t_{k}\right)-\tau \frac{\partial H^{(i)}}{\partial u}\left(t_{k}\right), \\
& t \in\left[t_{k} t_{k+1}\right], \quad k=0,1,2 \ldots, N .
\end{aligned}
$$

And easily its step value of $u^{(i+1)}\left(t_{k}\right)$, which is new input value at next step, is determined.

4.3. Optimal Control of the Automotive Longitudinal Dynamics. As it was mentioned before, the aim of this study is to control the longitudinal motion of the locomotive so that the fuel consumption is significantly reduced in the condition of maintaining performance characteristics, retaining driving abilities, or even changing longitudinal behavior parameters if possible. In the first step, the governing state space equations of the dynamic system must be derived. The index performance and the Hamiltonian function are then defined according to the desirable control input. Finally, the derivative of the Hamiltonian function relative to the control input is determined and then optimized [16].

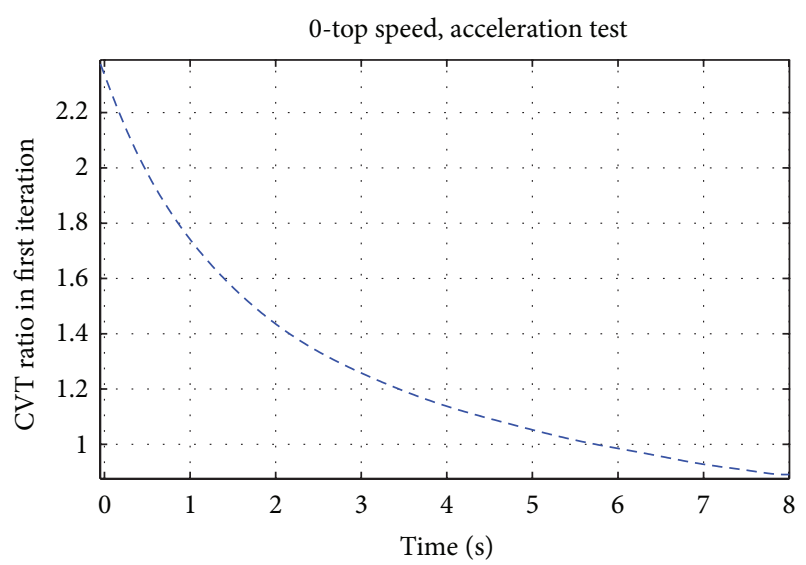

FIgURE 5: CVT ratio in first iteration.

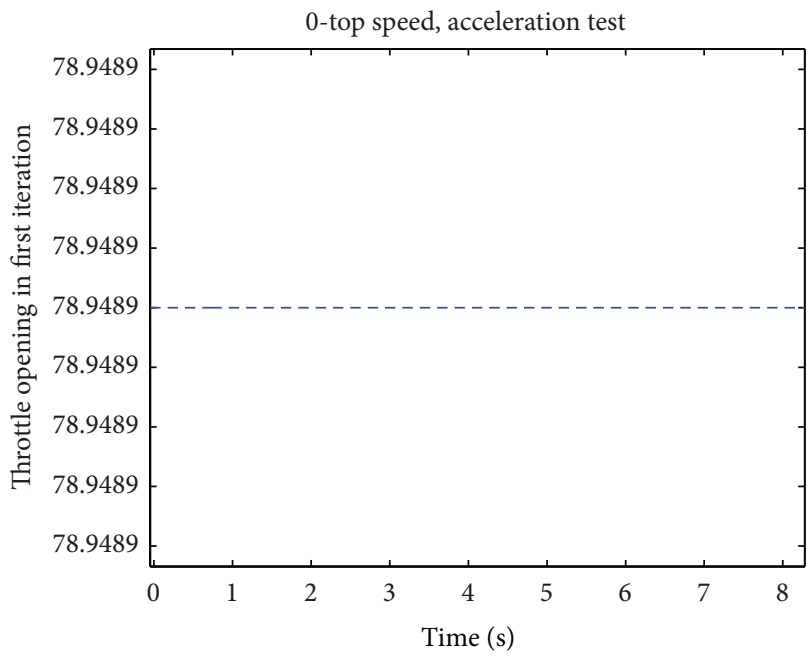

Figure 6: Throttle opening in first iteration.

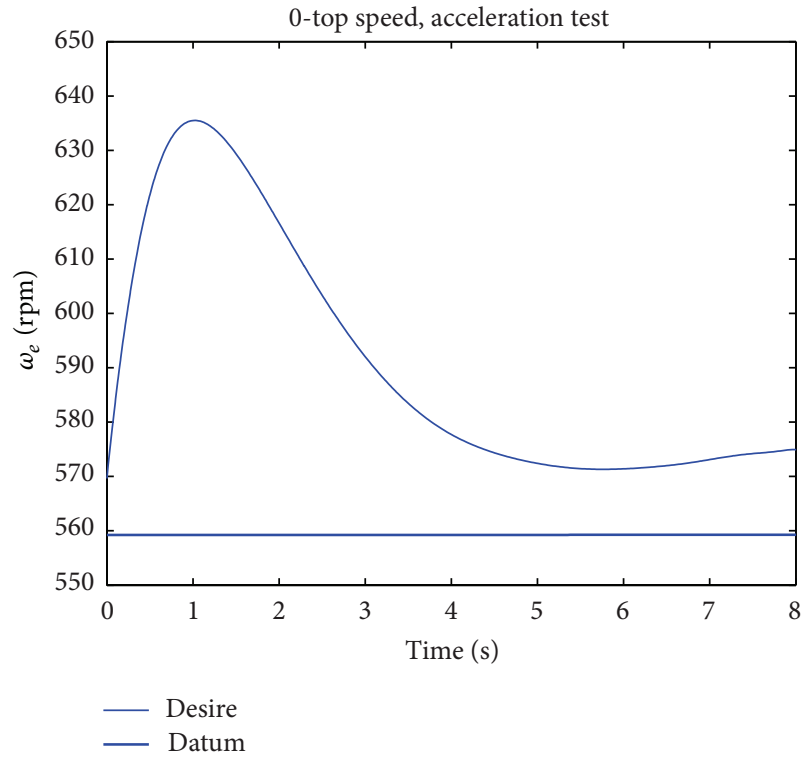

Figure 7: Engine speed. 


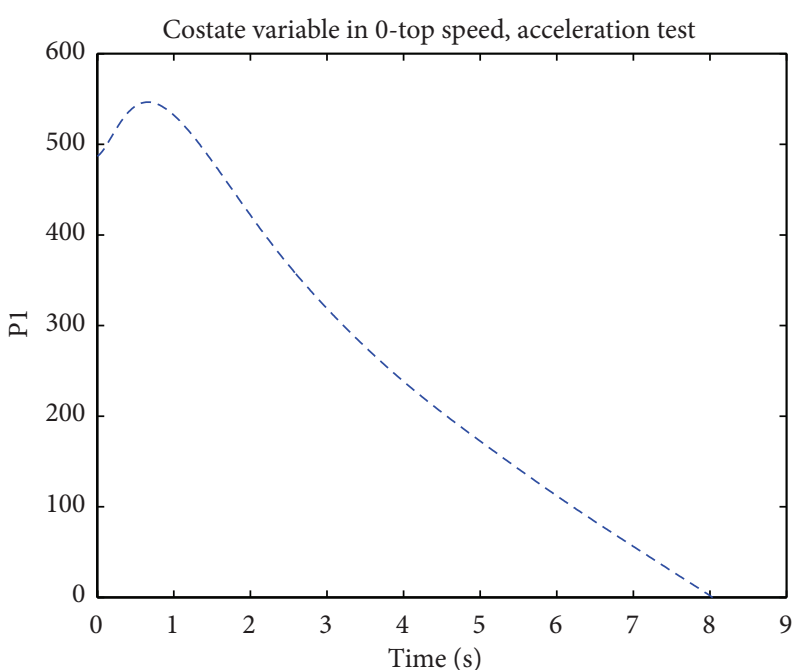

FIgURE 8: Costate parameter 1.

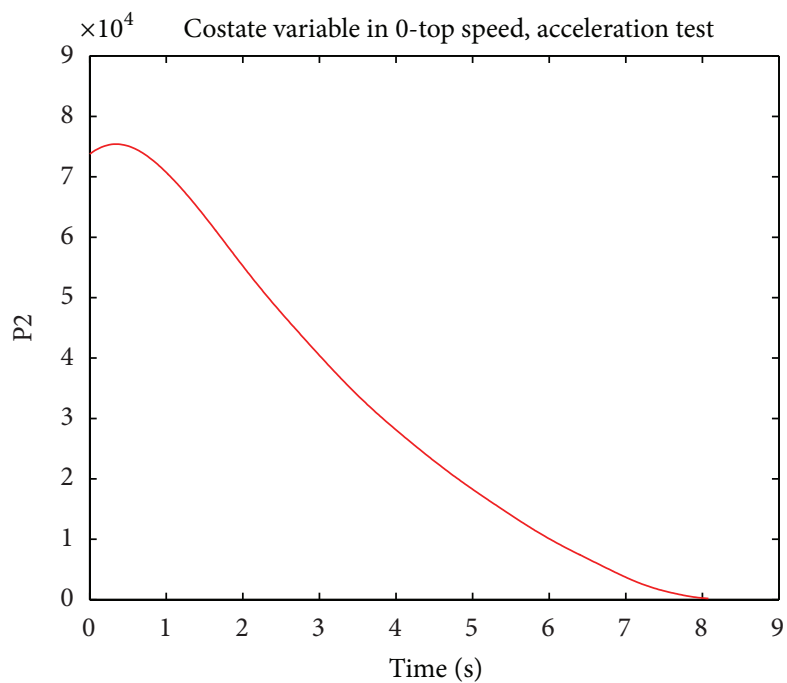

Figure 9: Costate parameter 2.

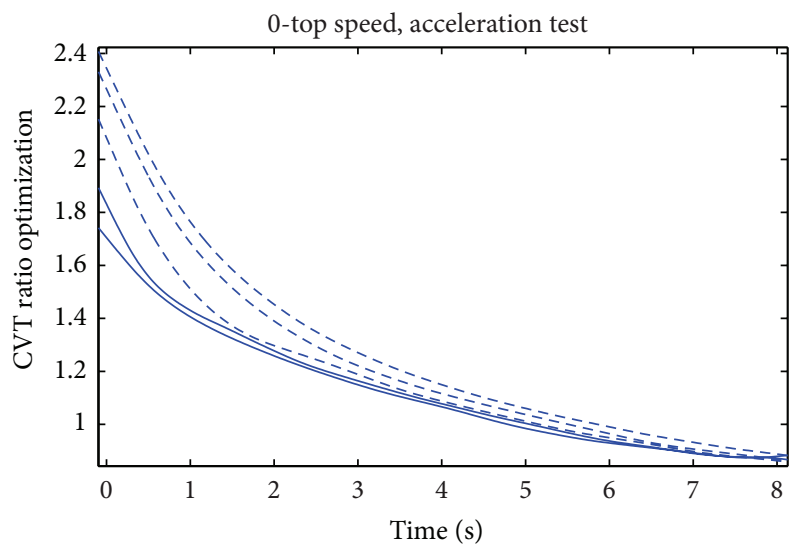

FIGURE 10: CVT ratio optimization.

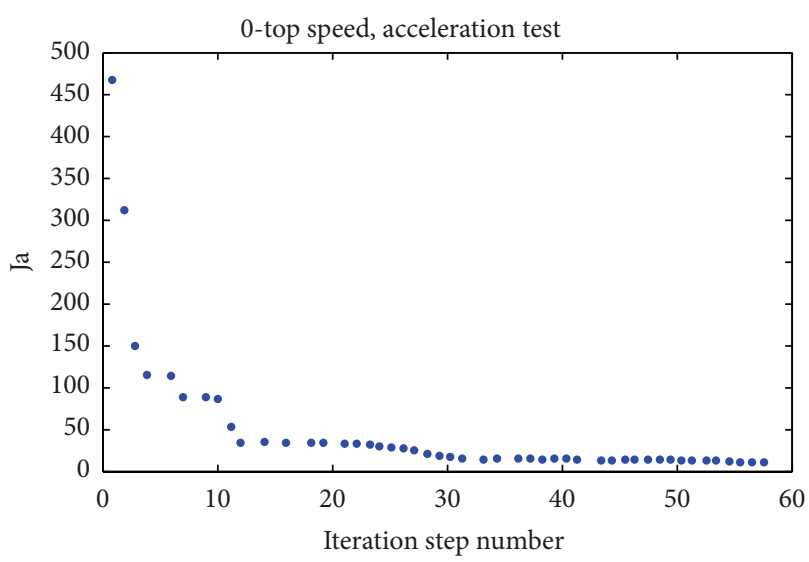

Figure 11: Performance index variations.

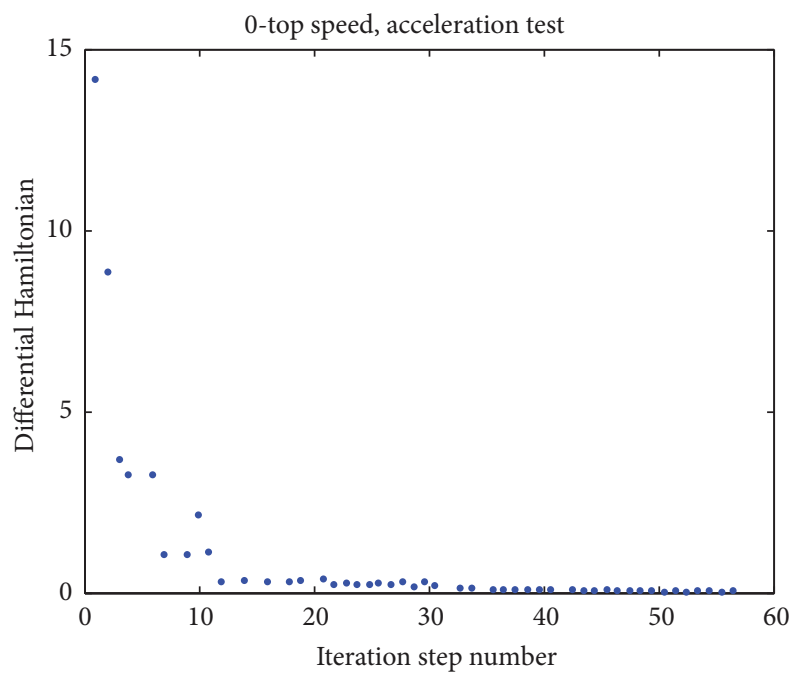

FIGURE 12: Hamiltonian differential variations.

4.3.1. Extraction of Governing Equations. Torque convertor is locked in this state, governing variables are engine speed and CVT ratio and control input is desired CVT ratio that must be followed by CVT first-order system.

\section{State Equations}

Consider the following:

$$
\begin{gathered}
\dot{U}_{\mathrm{CVT}}=\frac{U_{\text {desire }}-U_{\mathrm{CVT}}}{\tau_{\mathrm{CVT}}}=F_{1}, \\
\dot{\omega}_{e}=\left(T _ { t } * \left[J_{3} \cdot N_{f d} \cdot K_{2}+J_{4} \cdot \frac{K_{2}}{N_{f d}}+M \cdot r^{2} \cdot \frac{K_{2}}{N_{f d}}\right.\right. \\
-\frac{r^{3} \cdot 0.5 \cdot R_{o} \cdot C_{d} \cdot A+0.00000004 \cdot g \cdot M \cdot \omega_{e}^{2}}{N_{f d}^{2} \cdot U_{\mathrm{CVT}}^{2}} \\
\left.\left.+C_{r} \cdot r \cdot g \cdot M\right] \times\left(N_{f d} \cdot U_{\mathrm{CVT}}\right)^{-1}\right)
\end{gathered}
$$




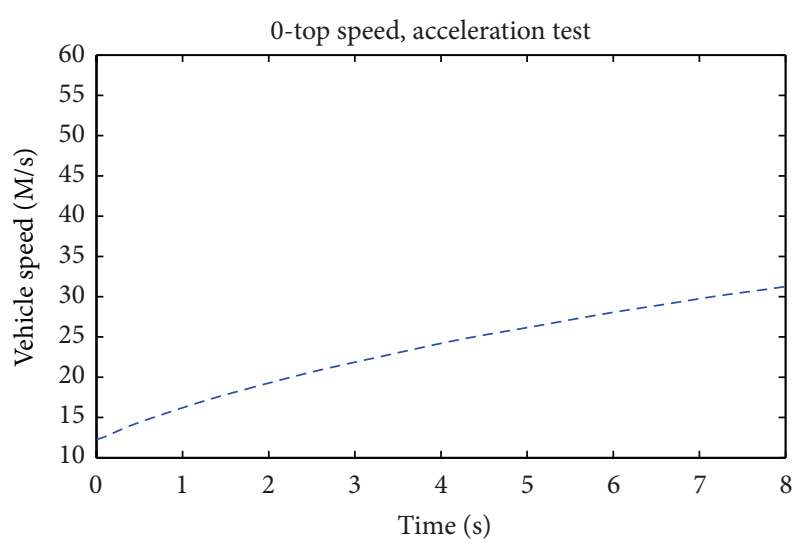

Figure 13: Vehicle speed.

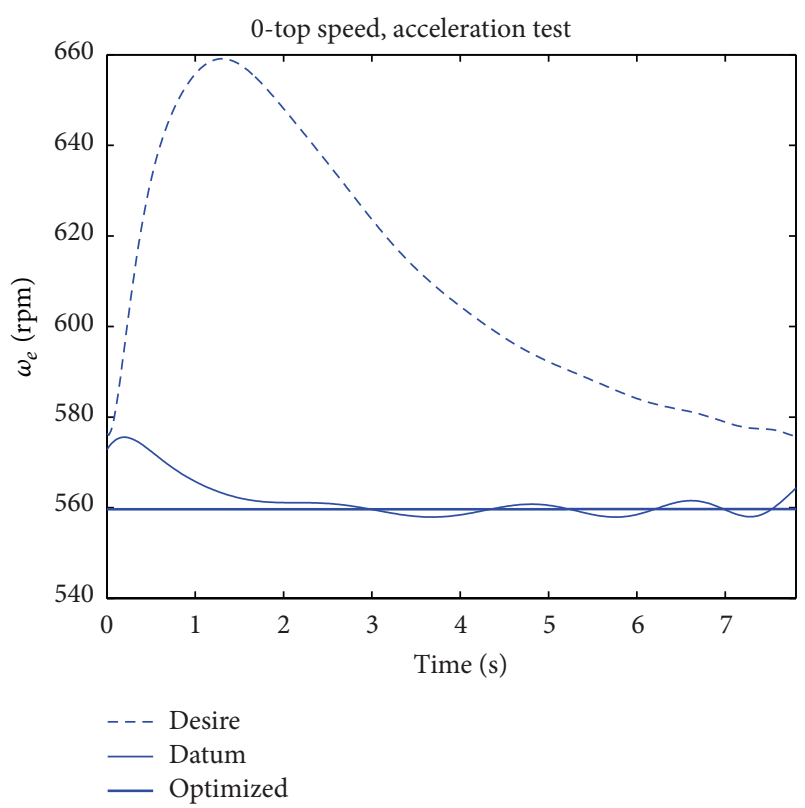

FIGURE 14: Engine speed.

$$
\begin{gathered}
\times\left(J_{2}+\frac{J_{3}}{U_{\mathrm{CVT}}^{2}}+\frac{J_{4}}{N_{f d}^{2} \cdot U_{\mathrm{CVT}}^{2}}+M \cdot \frac{r^{2}}{N_{f d}^{2} \cdot U_{\mathrm{CVT}}^{2}}\right)^{-1}=F_{2}, \\
F_{2}=\dot{U}_{\mathrm{CVT}}\left(\frac{\omega_{e}}{U_{\mathrm{CVT}}^{2}}\right) .
\end{gathered}
$$

Performance Index \& Hamiltonian Equation

$$
\begin{aligned}
J_{a}= & \int_{t_{o}}^{t_{f}}\left(\omega_{\mathrm{ool}}-\omega_{e}\right)^{2}+P_{1} *\left(\dot{U}_{\mathrm{CVT}}-F_{1}\right) \\
& +P_{2} *\left(\dot{\omega}_{e}-F_{2}\right) d t
\end{aligned}
$$

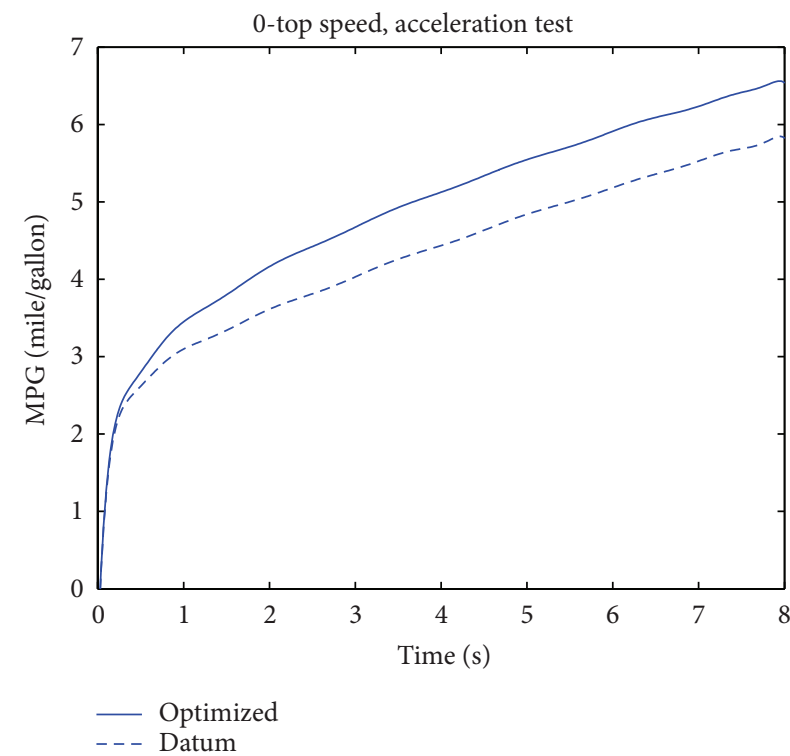

FIGURE 15: Specified parameter of fuel consumption.

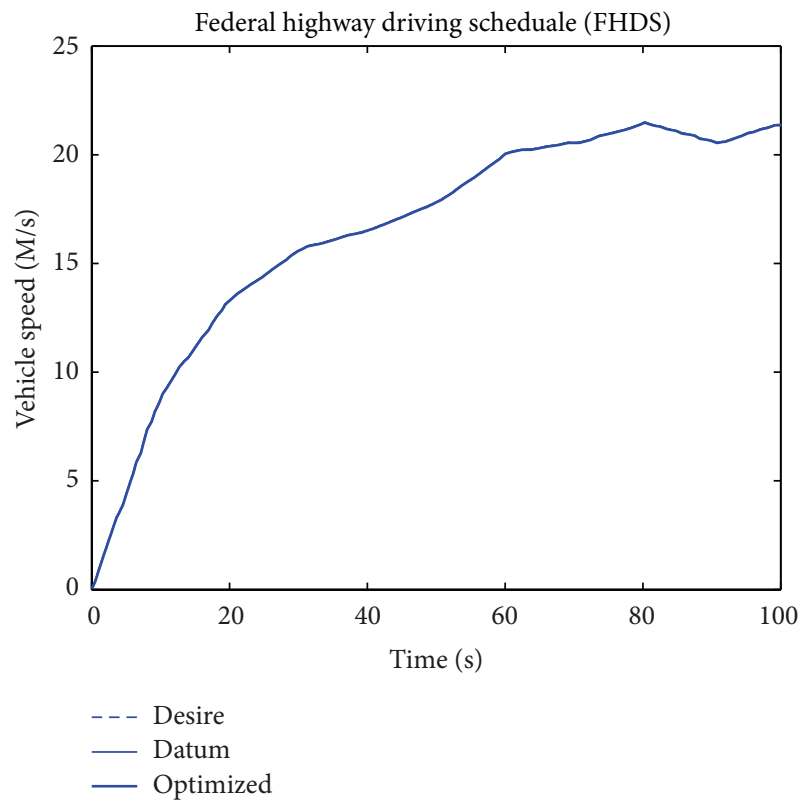

Figure 16: Federal highway driving cycle.

$$
\begin{aligned}
H_{\text {locked }}= & \left(\omega_{\mathrm{ool}}-\omega_{e}\right)^{2}+P_{1} * \dot{U}_{\mathrm{CVT}} \\
& +P_{2} * \dot{\omega}_{e} .
\end{aligned}
$$

\section{Costate Equations and Hamiltonian Differential}

$$
\dot{P}_{1}=-\frac{\partial H_{\text {locked }}}{\partial U_{\mathrm{CVT}}}
$$



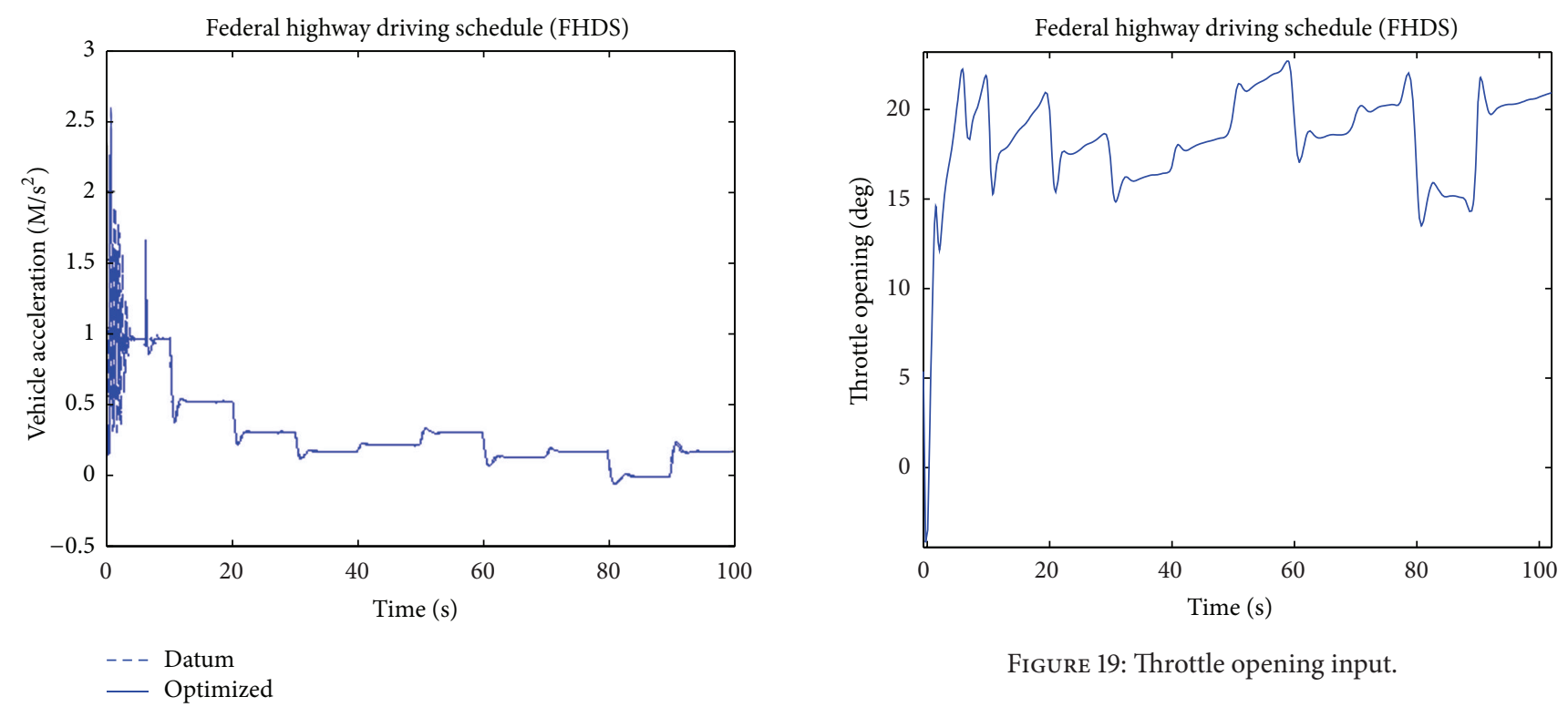

FIgUre 17: Acceleration Vehicle, (dashed), optimized (line).

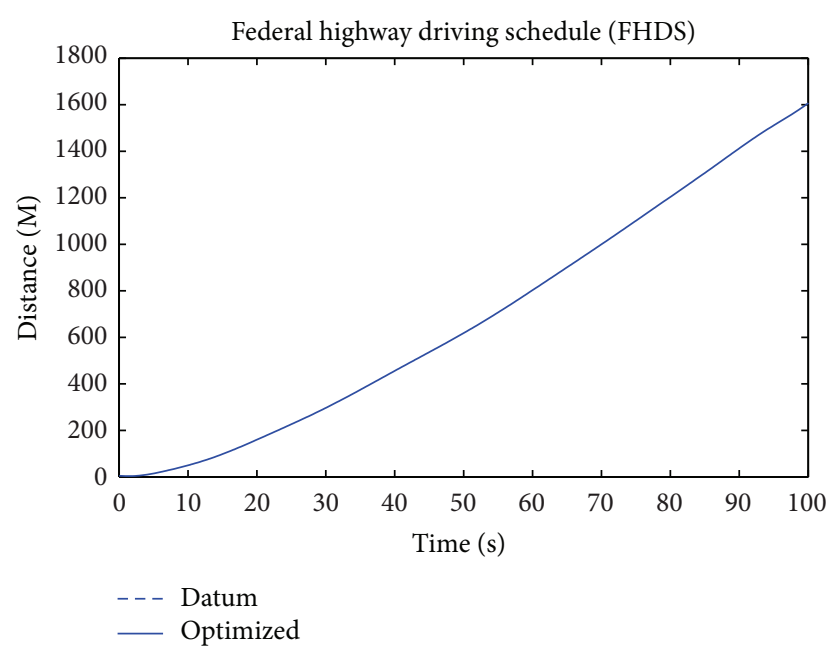

FIGURE 18: Distance, datum (dashed), optimized (line).

$$
\begin{gathered}
\dot{P}_{2}=-\frac{\partial H_{\text {locked }}}{\partial \omega_{e}}, \\
H \min _{\text {locked }}=\frac{\partial H_{\text {locked }}}{\partial U_{\text {CVT }}} .
\end{gathered}
$$

Mechanical Constrains

$$
\begin{gathered}
700<\omega_{e}<6000 \mathrm{rpm}, \\
0.5<U_{\mathrm{CVT}}<2.5 .
\end{gathered}
$$

Initial \& Final Conditions

$$
\begin{gathered}
x^{*}\left(t_{0}\right)=x_{0}, \\
U_{\mathrm{CVT}}^{*}\left(t_{0}\right)=U_{0}, \\
p_{1}^{*}\left(t_{f}\right)=\frac{\partial h}{\partial x}\left(x^{*}\left(t_{f}\right)\right)=0, \\
p_{2}^{*}\left(t_{f}\right)=\frac{\partial h}{\partial x}\left(x^{*}\left(t_{f}\right)\right)=0 .
\end{gathered}
$$

\section{Optimal Control Derivation}

A maneuver that is selected for longitudinal vehicle dynamic simulation is maximum acceleration test which is proposed to determine optimal control input. See Figures 5, 6, 7, 8, 9, 10, 11, 12, 13, 14, and 15 . 


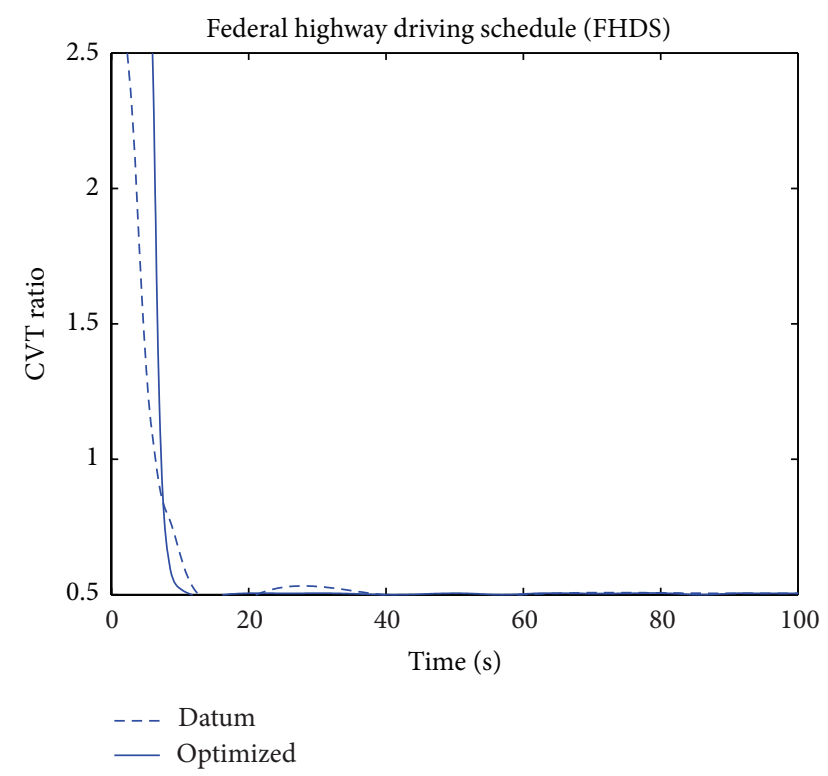

FIGURE 21: CVT Ratio, datum (dashed), optimized (line).

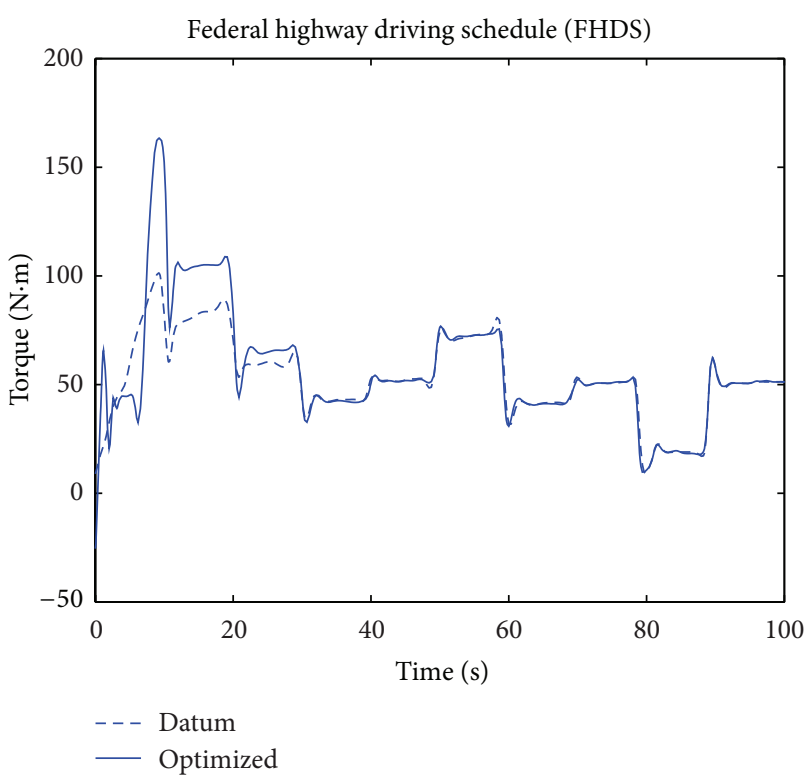

FIGURE 22: Engine torque, datum (dashed), optimized (line).

\section{Optimal Control Approach Test in Federal Highway Driving Cycle}

See Figures 16, 17, 18, 19, 20, 21, 22, 23, 24, and 25.

\section{Conclusion}

There exists indeed a need to investigate the fuel-optimal control solution and how much fuel consumption can be improved, because the classical control approaches are based on heuristic deliberations only. Thus in this paper, have been introduced an appropriate system model for whole powertrain and its subsystems. Optimal control is incapable

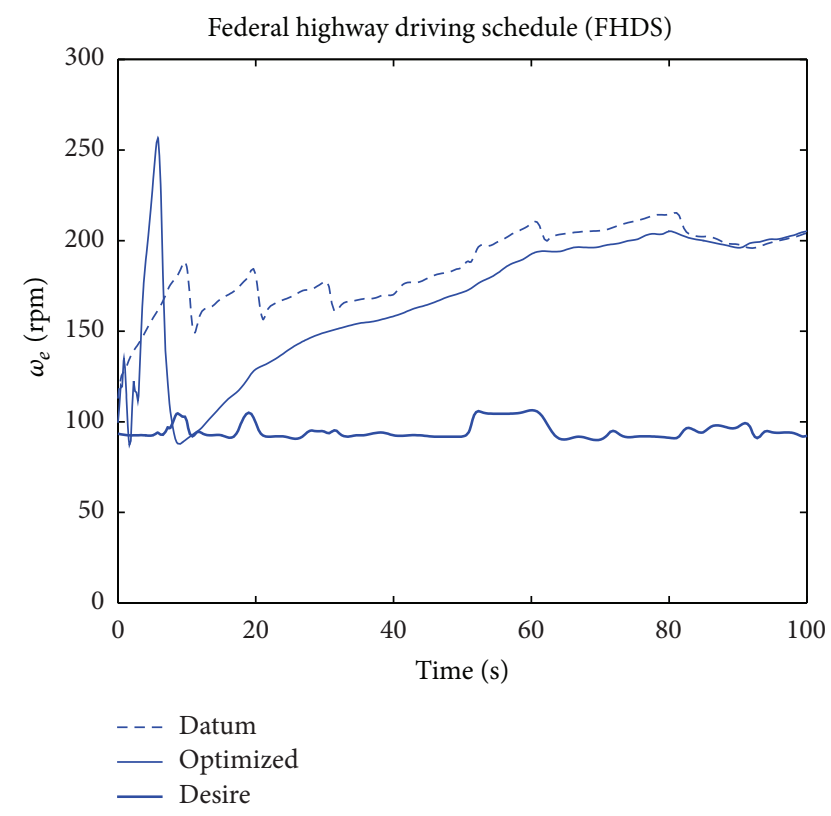

FIGURE 23: Engine Speed, datum (dashed), optimized (thin Line), desired (thick line).

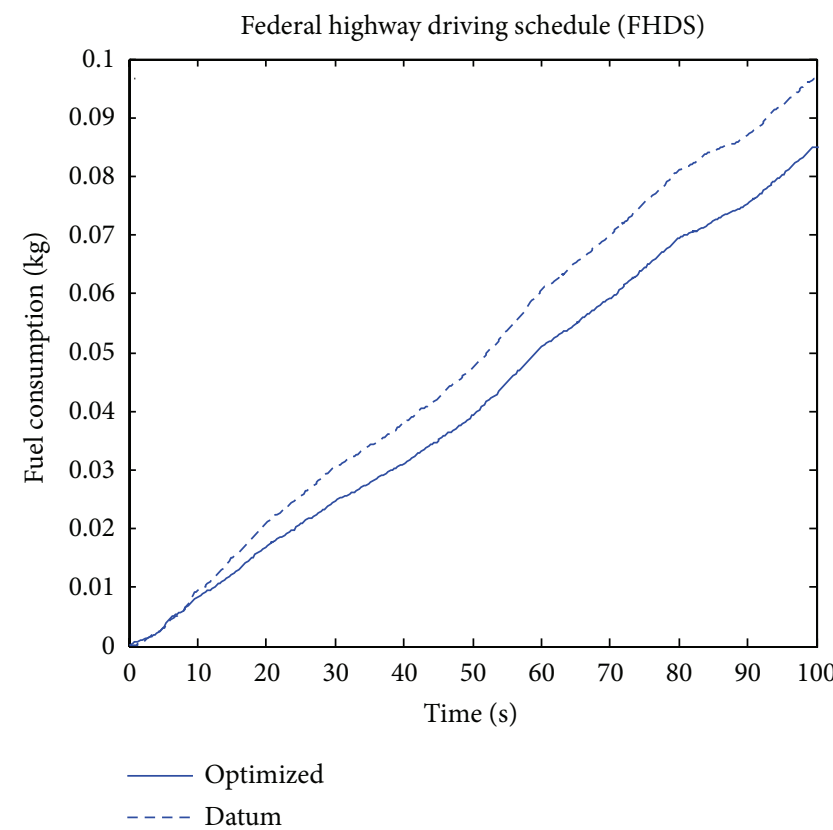

FIgURE 24: Fuel consumption, datum (dashed), and optimized (line).

of solving the CVT-based powertrains problem in transient conditions and it is defined in this paper; then the problem solved via nonlinear optimal control theory.

Regarding fuel consumption optimization, the strategy of following optimal performance curve of the engine is considered; thus, if the required power for the driver is supplied, there will be no decrease in the automotive performance as well as some improvements in the longitudinal performance. 


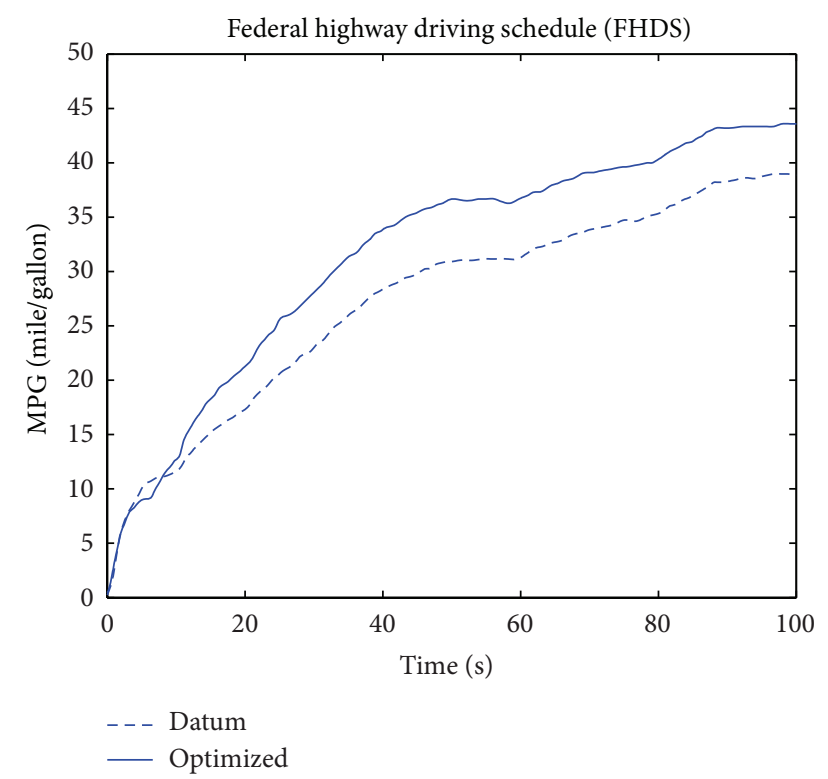

FIGURE 25: Specified parameters of fuel consumption Datum (dashed), optimized (line).

As it is shown in Figure 24, the fuel consumption index has a remarkable increase from 40.5 to 46.5 . Also, decreasing clutch engagement and optimal control strategy has improved fuel consumption about $11 \%$.

The improvements in fuel consumption are obtained by changing the controller software. Since no new powertrain components are needed, the costs associated with these changes are expected to be reasonably small.

\section{Conflict of Interests}

The authors declare that there is no conflict of interests regarding the publication of this article.

\section{References}

[1] R. Kazemi, R. Marzooghi, and S. M. Ansari Movahhed, "A tool for dynamic design of power train via modularity patterning," in Proceedings of the International Conference of Iranian Society of Mechanical Engineering (ISME '02), 2002.

[2] M. R. Peterson and J. M. Starly, "Nonlinear Vehicle Performance Simulation with Test Correction and Sensitivity Analysis," SAE 960521.

[3] F. Xie, J. Wang, and Y. Wang, "Modelling and co-simulation based on AMESim and Simulink for light passenger car with dual state CVT," in Proceedings of the International Workshop on Automobile, Power and Energy Engineering (APEE '11), pp. 363-368, April 2011.

[4] R. Kazemi, M. Kabganiyan, and M. Rajayi, "Nonlinear robust control of engine torque to the vehicle slip control," in Proceedings of the International Conference of Iranian Society of Mechanical Engineering (ISME '02), 2002.

[5] M. Zhou, X. Wang, and Y. Zhou, "Modeling and simulation of continuously variable transmission for passenger car," in Proceedings of the 1st International Forum On Strategic Technology (IFOST '06), pp. 100-103, October 2006.
[6] R. Pfiffner, Optimal Operation of CT-Based Powertrains [Ph.D. Dissertation], Swiss Federal Institute of Technology, Zurich, Switzerland, 2001.

[7] L. Kong and R. G. Parker, "Steady mechanics of layered, multiband belt drives used in continuously variable transmissions (CVT)," Mechanism and Machine Theory, vol. 43, no. 2, pp. 171$185,2008$.

[8] R. Krick, J. Tolstrup, A. Appelles, S. Henke, and M. Thumm, "The relevance of the phosphatidylinositolphosphat-binding motif FRRGT of Atg18 and Atg21 for the CVT pathway and autophagy," FEBS Letters, vol. 580, no. 19, pp. 4632-4638, 2006.

[9] R. Krick, J. Tolstrup, A. Appelles, S. Henke, and M. Thumm, "The relevance of the phosphatidylinositolphosphat-binding motif FRRGT of Atg18 and Atg21 for the CVT pathway and autophagy," FEBS Letters, vol. 580, no. 19, pp. 4632-4638, 2006.

[10] F. Xie, J. Wang, and Y. Wang, "Modelling and co-simulation based on AMESim and Simulink for light passenger car with dual state CVT," Procedia Engineering, vol. 16, pp. 363-368, 2011.

[11] G. Mantriota, "Performances of a parallel infinitely variable transmissions with a type II power flow," Mechanism and Machine Theory, vol. 37, no. 6, pp. 555-578, 2002.

[12] N. Srivastava and I. Haque, "Transient dynamics of metal Vbelt CVT: effects of band pack slip and friction characteristic," Mechanism and Machine Theory, vol. 43, no. 4, pp. 459-479, 2008.

[13] N. Srivastava and I. Haque, "A review on belt and chain continuously variable transmissions (CVT): dynamics and control," Mechanism and Machine Theory, vol. 44, no. 1, pp. 19-41, 2009.

[14] K. Hyunso and L. Jaeshin, "Analysis of belt behavior and slip characteristics for a metal V-belt CVT," Mechanism and Machine Theory, vol. 29, no. 6, pp. 865-876, 1994.

[15] D. Kirk, Optimal Control Theory: An Introduction, Prentice-Hill, Englewood Cliffs, NJ, USA, 1974.

[16] N. Srivastava and I. Haque, "A review on belt and chain continuously variable transmissions (CVT): dynamics and control," Mechanism and Machine Theory, vol. 44, no. 1, pp. 19-41, 2009. 

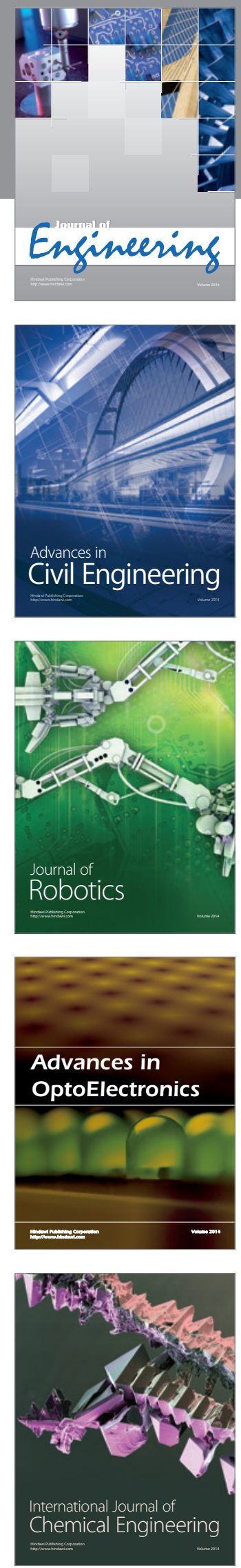

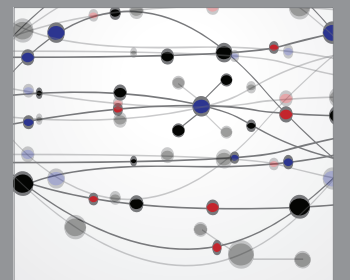

The Scientific World Journal
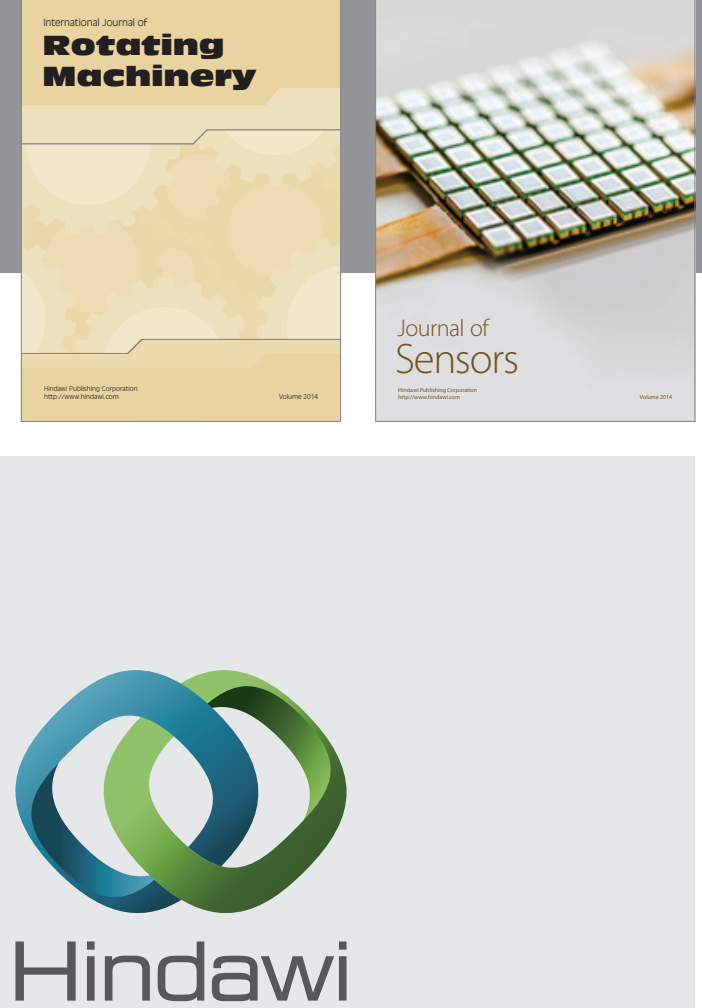

Submit your manuscripts at http://www.hindawi.com
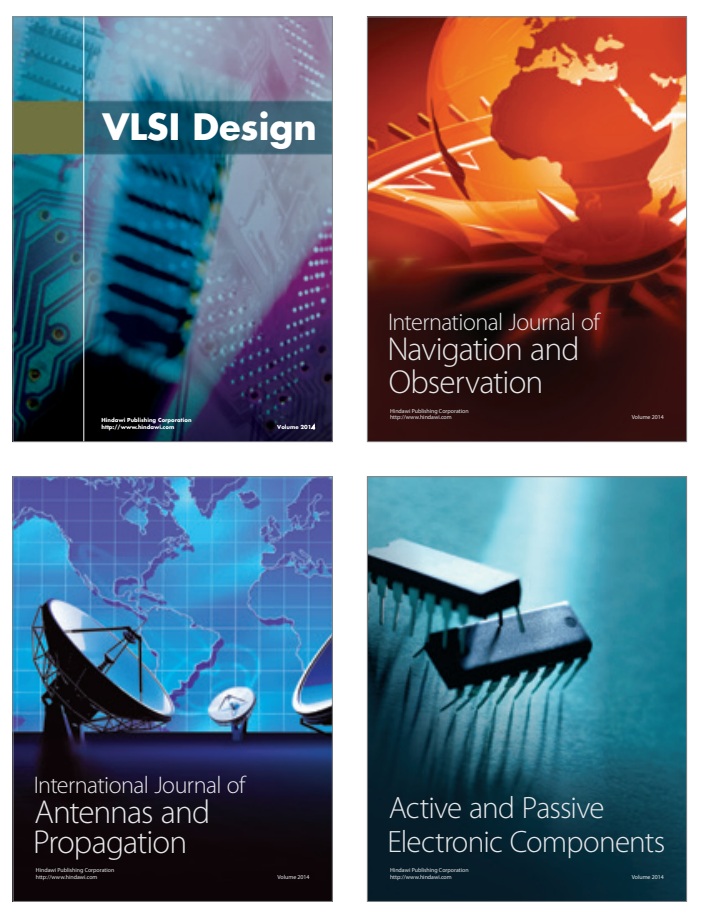
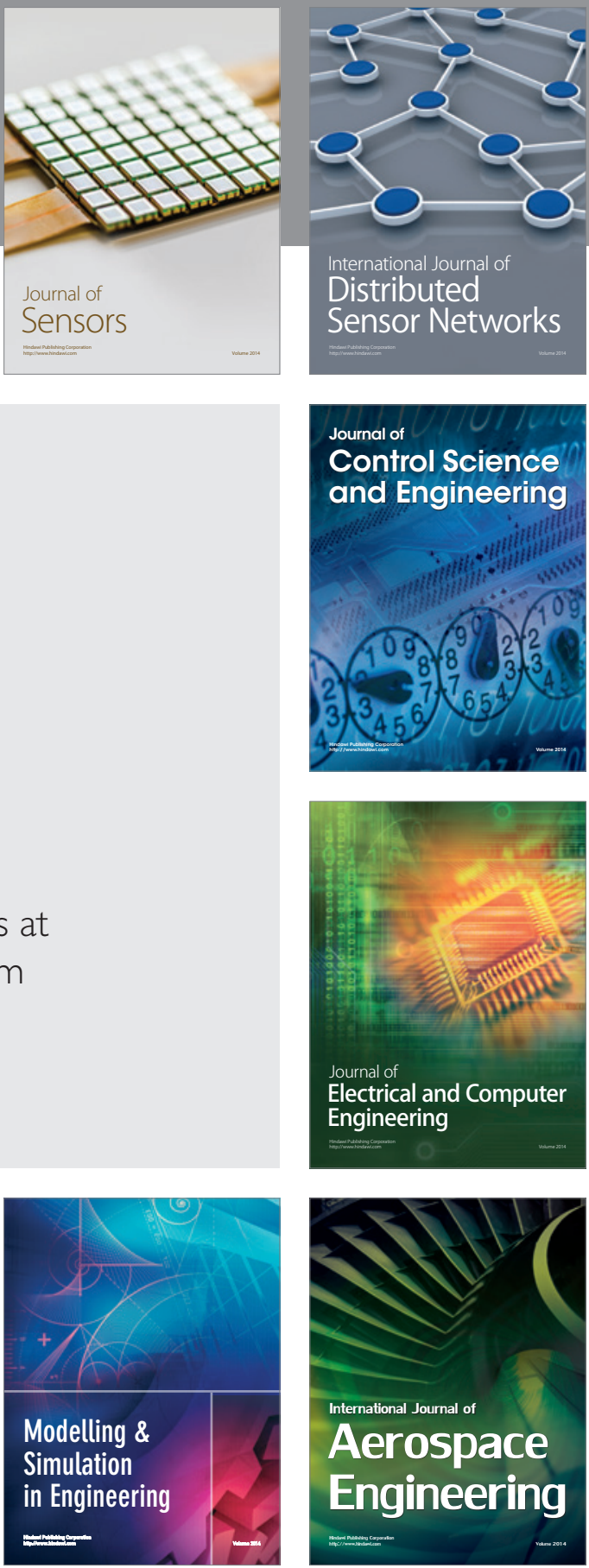

Journal of

Control Science

and Engineering
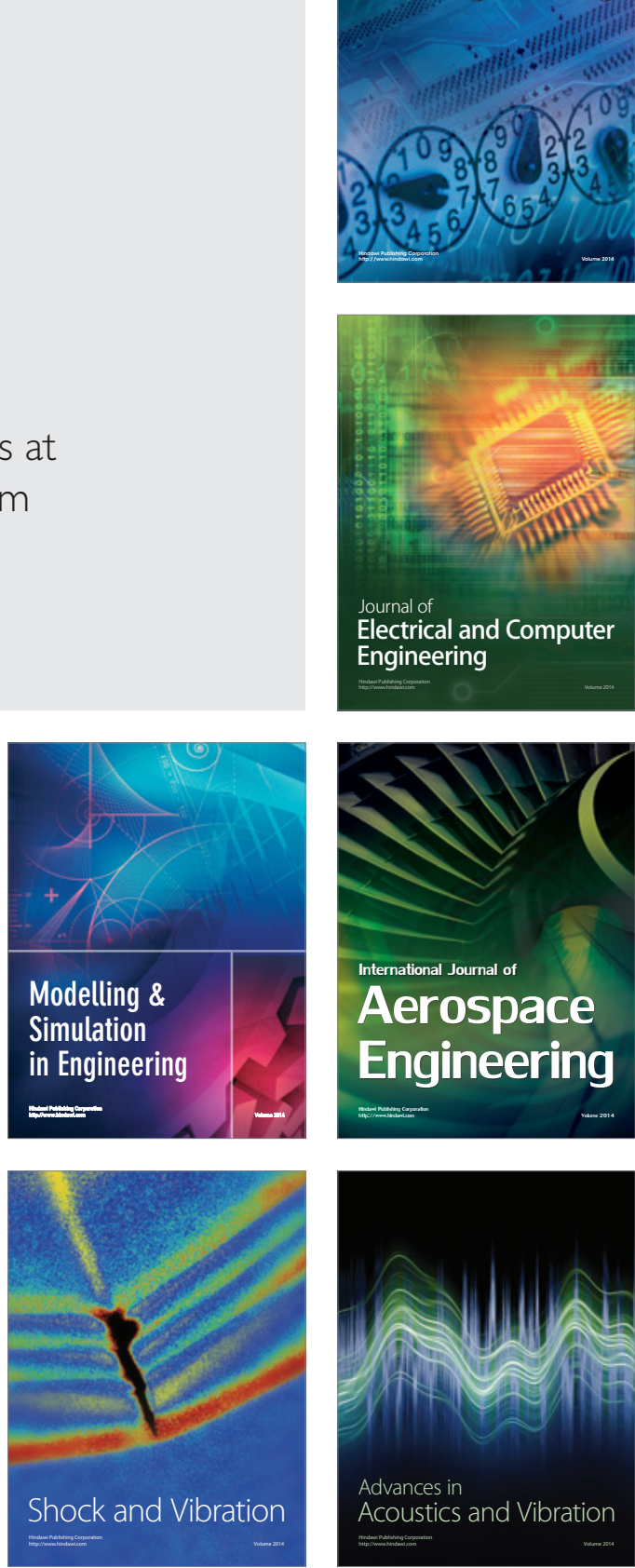